\title{
Engenharia Didática para o Teorema da Função Implícita: análises preliminares e a priori
}

Francisco Regis Vieira Alves

\begin{abstract}
Resumo
O teorema da função implícita se apresenta como assunto contemplado na abordagem tradicional dos compêndios de Cálculo no Brasil. Nesse artigo se descreve, de modo particular, duas etapas previstas pela Engenharia Didática ED. Assim, apresentam-se as fases de análise prévias e construção das situações/análises a priori. Enfatizam-se atividades descritas/estruturadas com apoio da tecnologia. A mediação afetada pela exploração adequada de softwares possibilita evitar determinados elementos que atuam como entraves a um entendimento conceitual amplo, inerente ao TFI. Desse modo, com a indicação e estruturação de situações-problema, se imprime maior ênfase na visualização e entendimento de propriedades qualitativas (gráfico-geométricas), e não apenas de natureza algorítmicas. Por fim, com os elementos questionados nos livros didáticos de Cálculo, proporciona-se a descrição de fatores atinentes à mediação didática do TFI, que assinalam caracteres que detém a possibilidade de controlar/prever as ações dos estudantes, bem como, promover um sentido amplo para a compreensão do teorema.
\end{abstract}

Palavras-chave: engenharia didática, teorema da função implícita, análises prévias, análise a priori.

\begin{abstract}
The implicit function theorem is presented as content covered in the traditional approach of textbooks of Calculus in Brazil. This article describes, in particular, two steps provided by Didactics Engineer - ED. Therefore, it presents the previous stages of analysis and construction of the situations/priori analysis. The emphasis in the described structured activities with technology support. The mediation is affected by a proper exploitation of the softwares that's enables to avoid certain elements that acts as barriers to a broader conceptual understanding inherent in TFI. Thereby indicating structured and problem situations, with more emphasis on visualization and understanding of qualitative properties (geometricgraph), and not just in the algorithmic nature. Finally, with the elements in textbooks questioned Calculation, provides the description of aspects pertaining to mediation didactic TFI, which indicate factors that has the ability to control / predict the actions of the students as well as promote a broad sense for understanding the theorem
\end{abstract}

Keywords: didactic engineering, implicit function theorem, previous analyzes a priori analysis.

\section{Introdução}

Reconhecidamente, quando consideramos os inúmeros conceitos que são objetos para o ensino do Cálculo a Várias Variáveis, patenteamos a relevância do Teorema da Função Implícita TFI. Seu caráter fundante no Cálculo e em Análise no $I R^{n}$ (LIMA, 2009) nos permitirá, nesse 
escrito, evidenciar um problema que concerne à sua interpretação gráfico-geométrica. Desse modo, na medida em que indicamos um problema ou entrave, efetuamos "o primeiro passo para uma Engenharia Didática" (DOUADY, 2008, p. 2). Douady (2008, p. 2) acrescenta ainda que:

"A engenharia didática, vista como metodologia de pesquisa, é caracterizada, em primeiro lugar, por um esquema experimental com base em realizações didáticas em sala de aula, isto é, a construção, realização, observação e análise de sessões de ensino."

Todavia, como mesmo apontam suas indicações, nesse trabalho, restringir-nos-emos apenas às fases (análises prévias e construção de situações/análises a priori) que permitem realizar a construção das sessões de ensino que detém a possibilidade de realizações didáticas em sala de aula, no contexto do ensino do Cálculo a Várias Variáveis - CVV. Em sintonia com a sistematização prevista pela Engenharia Didática (ARTIGUE, 1995; 1996; ROBINET, 1983) e recentes considerações sobre essa metodologia de pesquisa (ARTIGUE, 2008) apresentamos, na próxima seção, uma análise da organização matemática condicionada pelo nosso objeto teórico de interesse e estudo.

\section{Sobre o Teorema da Função Implícita}

Registramos uma seção, ou mesmo um capítulo, na maioria dos livros de Cálculo a Várias Variáveis (BUCK, 1965; GUIDORIZZI, 2010; LEITHOLD, 1999; STEWART, 2004; SWOKOWSKI, 1983; WIDER, 1947) dedicada ao Teorema da Função Implícita - TFI, assim como nos livros de Análise no $I R^{n}$ (APOSTOL, 1967; LIMA, 2009), nos quais, deparamos maior grau de generalidade.

Basicamente, a apresentação do problema matemático que descreve o TFI é caracterizada por: "dada uma função $\mathbf{F}$ e dado um ponto $\mathbf{p}$ em um conjunto de nível de $\mathbf{F}$, o teorema da função implícita garante, sob uma certa hipótese, quando este conjunto de nível de $\mathbf{F}$ é o gráfico de uma outra função f em uma vizinhança do ponto p." (BORTOLOSSI, 2009, p. 313).

Em seu caso particular, Lima (2009, p. 161-162) acresce a possibilidade da interpretação geométrica do TFI. Com efeito, assinalamos seu expediente, no sentido de significar simbologias do tipo $f^{-1}(c) \bigcap(I \times J)$, que comparecem no enunciado do TFI, no caso de equações definidas de modo implícito por $f(x, y)=c$. No caso de $f^{-1}(c) \cap(I \times J)$, o autor se refere ao gráfico de uma função $\xi: I \rightarrow J$ que, para cada $x \in I \subset I R$, existe um único $y \in J \subset I R$ com $f(x, \xi(x))=c$. Surpreendentemente, Lima (2009, p. 163) posterga a interpretação gráficogeométrica do TFI. Com tal intenção, acrescenta a noção de valor regular de uma função $f$, na qual temos as seguintes condições $f(x)=c(c t e)$ e $\nabla(f(x)) \neq 0$ (vetor gradiente não nulo).

Define também de um conjunto $C \subset I R^{2}$ é uma curva de classe $C^{k}(k \geq 0)$ quando $C$ é localmente o gráfico de uma função de classe $C^{k}$. Em termos topológicos, cada ponto $p \in C$ 
está contido num aberto $V \subset I R^{2}$, tal que $V \cap C$ é o gráfico de uma função $C^{k}$. Na figura 1, ressaltamos o esforço didático presente na abordagem de Lima $(2009$, p. 161). Observamos a presença de um valor regular ' $c$ ' e a região $I \times J \subset I R^{2}$, na qual, ele prevê a existência do gráfico de uma função $\xi(x)=y$ descrita de modo implícito. Cabe assinar, todavia, apenas em caráter motivacional preliminar, tendo em vista ser um livro de Análise no $I R^{n}$, os aspectos qualitativos cedem lugar, de modo peremptório, ao formalismo estruturante peculiar ao assunto.

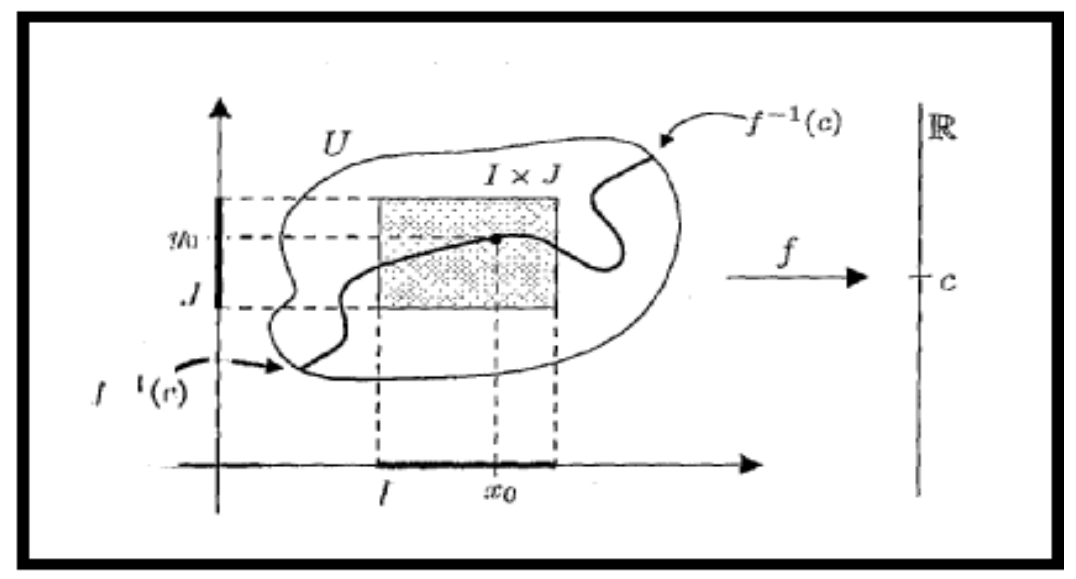

Figura 1 - Exemplo abordado em Leithod (1994, p. 1000)

Em sintonia com a evolução histórica e epistemológica, Krantz \& Parks (2002, p. 7) explicam que o pensamento heurístico que envolve a descrição do Teorema da Função Implícita TFI é fundamental, e constitui uma poderosa parte da fundamentação da moderna matemática. Ademais, "originalmente, concebido acerca de 200 anos atrás, para os estudos em Mecânica Celeste", o TFI, atualmente, possui várias formulações e é usado em muitos lugares por matemáticos em investigação, que envolvem o emprego de suas generalizações (JUNKINS; TURNER \& MANORAJAN, 2009), no campo de atuação dos matemáticos profissionais.

A gênese do interesse em torno do TFI é atribuída a Newton. No livro De Analysi per Equationes Infinitas, do ano de 1669 , Newton levantou a questão sobre a possibilidade de se expressar uma solução particular para a equação $Y^{3}+a^{2} Y-2 a^{3}+a x Y-x^{3}=0$, segundo o breve comentário de Krantz \& Parks (2002, p. 15). Estes autores reportam ainda que "Newton refinou o procedimento em torno deste problema, quando em 1670, publicou o manuscrito intitulado De Methodis Serierum et Fluxionum." (Idem, 2002, p. 15).

Credita-se a Cauchy (1789-1857) a primeira forma rigorosa do Teorema da Função Implícita (KRANTZ \& PARKS, 2002, p. 27). Trabalhando no contexto de funções holomorfas, Cauchy, demonstrou a existência de uma função implicitamente definida, sob condições e hipóteses suficientes. Por outro lado, nosso interesse maior neste trabalho, diz respeito à classe de funções de duas e de três variáveis reais. Assim, a formulação mais conhecida é devida a Dini 
(1845-1918) em 1870. A prova e/ou sua demonstração se apóia "no processo de indução matemática sobre o número de variáveis dependentes" (KRANTZ \& PARKS, 2002, p. 36).

Um enunciado, em termos atuais, do TFI é discutido por Scarpello \& Ritelli (2002, p. 172), Consideremos, para inicio de nossa discussão, a seguinte equação em termos de duas variáveis $y^{5}+16 y-32 x^{3}+32 x=0$. Reparemos, com base na figura 1 , que o locus descrito por tal equação, define um subconjunto do $I R^{2}$ que, aparentemente, possui as propriedades de ser o gráfico de uma função de y como variável de $x$, todavia, Krantz \& Parks (2002, p. 2) sublinham que "nenhum fórmula para tal função existe.". Não obstante, Krantz \& Parks (2002, p. 2) acrescentam ainda que "em contraste com a ingênua definição de função como uma fórmula, a moderna, a definição conjuntiva é formulada em termos do gráfico de uma função.". No caso da equação $y^{5}+16 y-32 x^{3}+32 x=0\left(^{*}\right)$, pode-se verificar que, para cada $x \in I R$, existe um único $y \in I R$, de modo que o par $(x, y)$ satisfaz a equação $\left(^{*}\right)$. Na fig. 2 exibimos seu comportamento no $I R^{2}$.

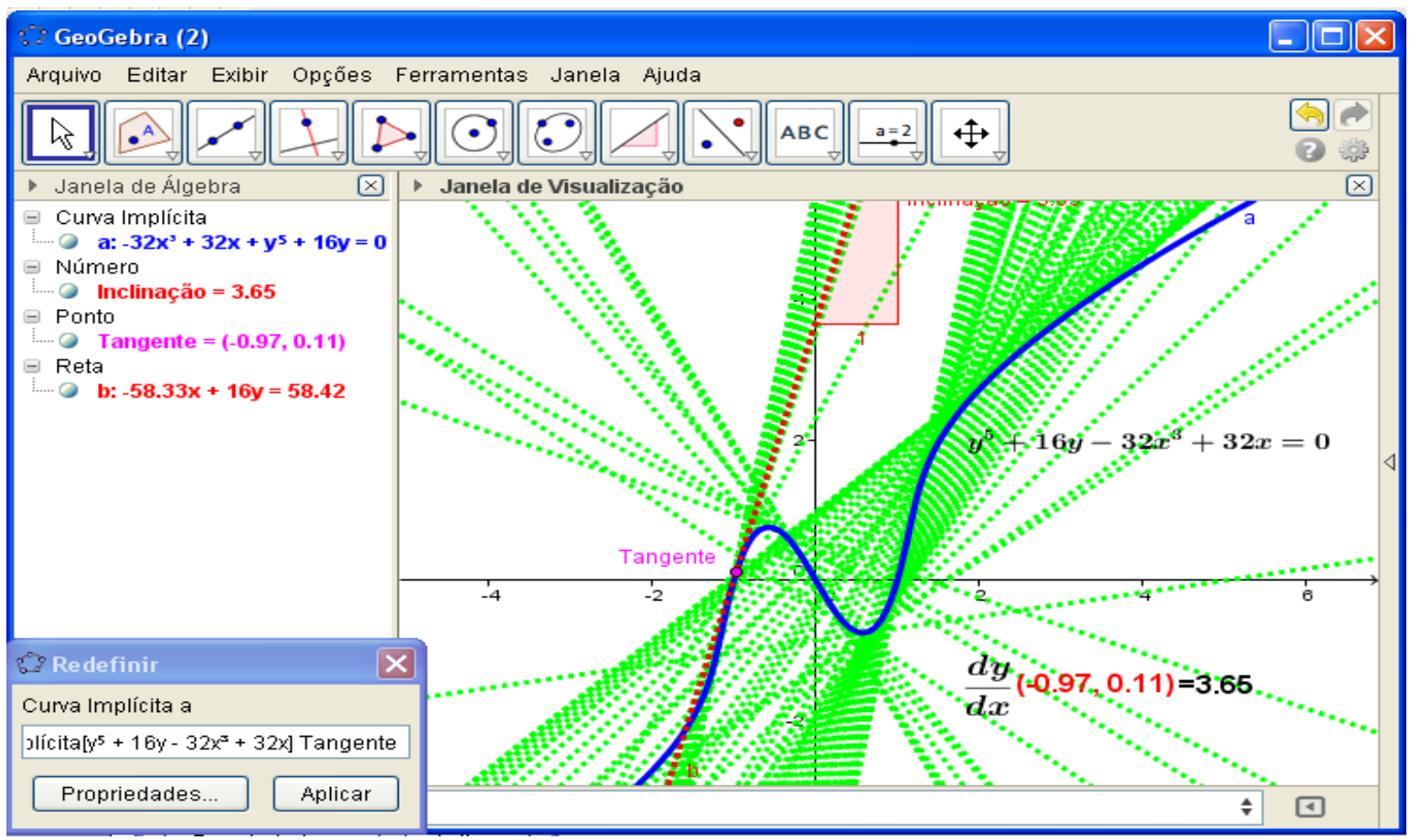

Figura 2 - Curva de nível discutida em Krantz \& Parks (2002, p. 2)

\section{Sua apresentação nos livros de Cálculo}

Nesta seção, evidenciaremos e identificaremos os elementos que se sobressaem a partir da proposta de abordagem de certos compêndios especializados, tradicionalmente adotados no Brasil, no que concerne ao TFI. Distinguiremos, todavia, duas classes de problemas: (a) problemas envolvendo curvas de nível do tipo $f(x, y)=c$; (b) problemas envolvendo superfícies de nível do tipo $f(x, y, z)=c$. Nosso primeiro exemplo é extraído de Leithold (1999). Nesse sentido, observamos que, na figura 3, o referido autor imprime ênfase ao caráter algébrico dos conceitos

DOI: Em andamento. 
envolvidos. Envolvendo um problema da classe (a), o significado do símbolo $d y / d x$ é reduzido ao caráter analítico. O autor não faz nenhuma indicação de seu contexto histórico e/ou epistemológico, concernente ao momento de gênese e das ideias heurísticas do teorema.

\section{EXEMPLO 1 Dado que $y$ é uma função implícita de $x$ definida por $F(x, y)=$ $=x^{3}+y \cos x=0$, determine $\frac{d y}{d x}$.}

Figura 3 - Exemplo abordado em Leithod (1994, p. 1000)

Na figura 4, Leithold (1999) sugere um problema envolvendo a intersecção de objetos. A situação envolve duas superfícies de nível. 0 estilo em nada difere do caso anterior.

\section{EXEMPLO 6 Dado que}

$$
F(x, y, z)=x^{2}+y^{2}+z^{2}-1=0 \text { queremos calcular } \frac{d y}{d x} \mathrm{e} \frac{d z}{d x} .
$$

$$
G(x, y, z)=x^{2}-y^{2}-2 z^{2}-1=0
$$

Figura 4 -Exemplo abordado em Leithod (1994, p. 1003)

Guidorizzi (2010) acentua o caráter formalista, que prioriza o quadro algébrico para lidar e manipular os objetos matemáticos. Reparemos nos enunciado abaixo, a inexistência de ulteriores intenções didáticas, que não vão além de explicitar, de novo, o símbolo $d y / d x$ (ver fig. 5).

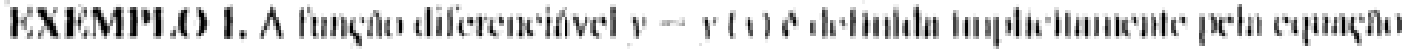

$$
y^{3}+x y+x^{1}+1
$$

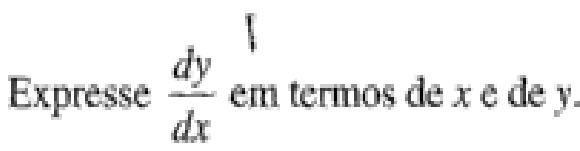

Figura 5 - Exemplo abordado em Guidorizzi (2010, p. 328)

Vale assinalar que os livros em outros idiomas fortalecem alguns dos aspectos questionados nos parágrafos anteriores. Na figura 6, Ayres \& Mendelson (1994) economizam, ao 
máximo, o uso da língua materna e acentuam as inferências de amparo lógico. Ao final, os símbolos $\partial z / \partial x$ e $\partial z / \partial y$ são indicados, sem uma intenção didática descritiva/qualitativa do TFI.

5. Find $\partial z / \partial x$ and $\partial z / \partial y$, given $\sin x y+\sin y z+\sin z x=1$.

Set $F(x, y, z)=\sin x y+\sin y z+\sin z x-1$; then

$$
\frac{\partial F}{\partial x}=y \cos x y+z \cos z x \quad \frac{\partial F}{\partial y}=x \cos x y+z \cos y z \quad \frac{\partial F}{\partial z}=y \cos y z+x \cos z x
$$

and $\quad \frac{\partial z}{\partial x}=-\frac{\partial F / \partial x}{\partial F / \partial z}=-\frac{y \cos x y+z \cos z x}{y \cos y z+x \cos z x} \quad \frac{\partial z}{\partial y}=-\frac{\partial F / \partial y}{\partial F / \partial z}=-\frac{x \cos x y+z \cos y z}{y \cos y z+x \cos z x}$

Figura 6 - Exemplo abordado em Ayres \& Mendelson (1994, p. 395)

Patenteamos o caráter algébrico/manipulatório preponderante, na quase totalidade das atividades propostas e exercícios resolvidos nos livros consultados. Outrossim, apontamos nos excertos de trechos de livros, o caráter formalista e a negligencia dos aspectos perceptuais gráfico-geométricos (qualitativos) atinentes ao TFI. Reparemos ainda que a noção de "existência" de uma função, da mesma classe de diferenciabilidade da função inicial, prevista pela tese do teorema, é esquecida, por completo. Nenhum elemento funciona no sentido de estimular a visualização e o caráter topológico (existência e tamanho da bola centrada no ponto), de aplicação local do TFI, em cada situação.

Na obra de Pinto \& Morgado (2000) registramos o empenho na atribuição de significado para as derivadas parciais, denotadas (de modo simplificado) por $\partial z / \partial x$ e $\partial z / \partial y$, entretanto, os autores perdem a oportunidade de estabelecer o link conceitual entre as derivadas, calculadas no ponto, que determinam as declividades de retas, o plano determinado por essas retas, bem como, a existência local de um gráfico de uma função (garantida existência pelo TFI). O caráter imperativo das sentenças lingüísticas presentes no enunciado impulsiona a reprodução e replicação irrefletida dos modelos matemáticos vinculados ao exemplo (ver figura 7).

Exemplo A.6: Verifique que a equação $x^{3}+3 y^{2}+8 x z^{2}-3 z^{3} y=9$ define $z$
como função de $x$ e $y$ numa vizinhança do ponto $(1,0,1)$, e calcule $\frac{\partial z}{\partial x}(1,0)$ e
$\frac{\partial z}{\partial y}(1,0)$.

Figura 7 - Exemplo abordado em Pinto \& Morgado (2000, p. 315) 
Stewart (2004, p. 922-923) não se distancia da tônica anterior questionada. O enunciado to TFI é omitido. A orientação da leitura de outros livros, nos quais, se encontra a demonstração do TFI é facilmente identificada. Na seção de exercícios (STEWART, 2004, p. 924), observamos ainda que o predomínio hegemônico e a exigência da simples aplicação de regras de inferência, de natureza lógica, é um caráter invariante neste compêndio.

Para concluir essa seção, recordamos que a metodologia de pesquisa nominada Engenharia Didática (ARTIGUE, 1996), tem sido utilizada design de investigação, numa perspectiva de complementaridade (ARTIGUE, 2008; BROUSSEAU, 1986) com outras teorias, desde a década de 80. Sublinhamos o estudo de Camacho \& Aguirre (2001) que discute um desenho didático para a apresentação do conceito de limite. Esses autores dão ênfase nas etapas de analise preliminar e análise a priori. De modo semelhante, neste artigo, escolhemos o TFI como objeto matemático investigado. Doravante, apresentamos as duas fases iniciais de uma ED, com o tema TFI.

\section{Análises preliminares ou prévias}

Como assinalamos na introdução desse escrito, do ponto de vista do design de investigação adotado, assumimos a sistemática prevista pela ED. Oriundo de uma vasta tradição acadêmica, sabemos que a concepção de pesquisa em Engenharia Didática - ED compara a forma de trabalho didático do professor com a maneira de trabalho do engenheiro que, para realizar projetos, se apóia sobre conhecimentos científicos de seu domínio (ARTIGUE, 1996, p. 243).

$E$, no que concerne aos momentos ou fases da investigação, distinguimos: as análises preliminares, analises a priori, a etapa da experimentação e introdução ao movimento de todo o aparato metodológico construído, validação e análises a posteriori. Ora, como assinalado nas seções anteriores, restringir-nos-emos aos primeiros dois momentos previstos por Artigue (1996).

Sendo assim, no âmbito das análises preliminares ou prévias, nessa seção, identificaremos problemas de ensino e de aprendizagem vinculados ao TFI. Com base e amparo em tal sistemática, delinearemos questões (situações problema), formularemos determinadas hipóteses, que detém a possibilidade de serem investigadas, a posteriori, de modo empírico. Dois elementos devem ser evidenciados nessa etapa, de acordo com Almouloud (2007, p. 172), a saber: (i) estudo da organização matemática; (ii) análise didática do objeto matemático escolhido.

De modo específico, concernente ao item (i), no atemos: estudo da gênese histórica envolvendo do TFI (apresentada na seção 2); sua funcionalidade atual na Matemática (limitações para o uso didático); obstáculos relativos ao TFI (conceitos reconhecidamente complexos vinculados do TFI); a estrutura atual do ensino do TFI e seus efeitos. Relativo ao item (ii) apontamos a relevância da análise de livros didáticos (apresentada na seção 3). Uma análise de livros de Cálculo deve contemplar: o papel da história do TFI; os obstáculos epistemológicos (ROBINET, 1983, p. 4) identificáveis na abordagem dos autores; antever as possíveis concepções 
dos alunos (dimensão cognitiva), oriundas a partir da abordagem proposta. Desse modo, concluímos:

- os autores de livros enfatizam o caráter algorítmico condicionado pelo TFI;

- a noção de existência matemática é admitida de modo automático pelos autores;

- os aspectos topológicos locais, de aplicação do TFI são desconsiderados;

- a visualização e a significação gráfico-geométrica das simbologias são negligenciadas.

Com base nesses entraves, formulamos as seguintes hipóteses de trabalho que não serão objeto de investigação empírica nesse estudo teórico, entretanto, podem ser objeto de interesse em outros estudos empíricos, envolvendo a mesma temática ou outro tópico no ensino do CVV:

1a) Uma mediação condicionada pela abordagem standard dos livros de CVV não promove a visualização e o entendimento gráfico-geométrico (local) atinente ao TFI;

2a) Situações de aprendizagem definidas pelos exercícios propostos pelos autores de livros de CVV permitem apenas a aquisição de habilidades manipulativas de equações, que incidem ou acarretam em resultados de significado restrito, sem um entendimento amplo do TFI.

Na próxima seção abordaremos algumas situações problema, com vistas à aprendizagem, em consonância com a descrição de Brousseau (1986, p. 414). As variáveis didáticas serão apontadas e, sua manipulação e exploração didática conveniente devem estimular novos cenários para efetiva aprendizagem, na medida em que indicaremos elementos de mediação e transmissão dos saberes, que detém a possibilidade de evitar os entraves anteriormente formulados.

\section{Construção das situações e Análises a priori}

Nessa fase de ED, elaboraremos e analisaremos uma sequência de situações-problema envolvendo o TFI. Responderemos algumas questões indicadas nas sessões anteriores, todavia, não ensejamos validar essas hipóteses de investigação, posto que, não procederemos as análises a posteriori. Para efeito de maior sistematização, assumiremos que uma situação-problema envolve "a escolha de questões abertas e/ou fechadas numa situação matematizada ou menos matematizada, vinculada a um campo de problemas colocados em um ou vários domínio de saber." (ALMOULOUD, 2007, p. 174). Vale observar que, no campo de saberes referenciados por Almouloud (2007), é possível, tendo em vista o nível elementar da Matemática, considerar situações "menos matematizada". Entretanto, em nosso caso, o modelo matemático condiciona, fortemente, todas as estratégias e as ações e decisões dos aprendizes. Essa variável didática é prevista, de modo geral, por Brousseau (1986, p. 412).

Não obstante, nosso objeto de atenção (um teorema em Matemática e sua aplicação), pertencente a um corpus teórico-formal, implica em fortes condicionantes oriundos da própria 
construção/demonstração e descrição do TFI. Outrossim, levaremos em consideração, com vistas à estruturação das situações-problema, as seguintes características apontadas por Almouloud (2007): situações que devem colocar em jogo um campo conceitual em que se deseja efetivamente explorar; os conhecimentos antigos não são suficientes para a resolução completa do problema; o problema envolve vários domínios do conhecimento. Assinalamos acima apenas parte das características apontadas por Almouloud (2007, p. 174).

Nesse sentido, vale distinguir e pormenorizar os seguintes elementos: os problemas que tencionamos explorar envolvem domínios analíticos e gráfico-geométricos, entretanto, os conhecimentos antigos (no caso os saberes relacionados com o TFI) devem ser suficientes para a resolução. Além disso, nas situações que buscamos apresentar, desejamos que "elas permitam adaptações dos alunos, na medida em que tomam decisões e as modificam" (BROUSSEAU, 1986, p. 440). Quando visamos descrever situações de ensino fundamentadas de uma Matemática oriunda de nível avançado, o campo conceitual é condicionado, por vezes, por uma definição formal ou um teorema estruturante. No nosso caso o TFI, assinalamos que:

- Dado o caráter de não trivialidade do TFI (quantidade de hipóteses e a descrição da tese), as situações-problema requerem conhecimentos suficientes para sua resolução, entretanto, a abordagem será determinante. Desse modo, a visualização proporcionada pelos softwares deverá ser uma variável didática recorrente no cenário de aprendizagem apresentado aos estudantes.

Assumimos posição concorde com Almouloud (2007, p. 174) ao acentuar que "as atividades devem ser concebidas, levando-se em consideração os resultados dos estudos prévios", e terão por objetivos: auxiliar o aluno na construção de conhecimentos e saberes de uma maneira construtiva e significativa; desenvolver certas habilidades como, por exemplo, saber ler, utilizar as diferentes representações matemáticas e desenvolver raciocínio dedutivo.

Para concluir essa seção, vale destacar que "os objetivos da análise a priori devem determinar que as escolhas realizadas permitam o controle do comportamento dos alunos e seu significado". (ARTIGUE, 1995, p. 45). Desse modo, as escolhas e descrição de ações futuras, nessa seção, são fundamentadas em pressupostos teóricos, que devem permitir o controle didático da transposição didática e do sentido das ações futuras envolvendo a mediação de saberes.

O controle didático que propomos é passível de certa hierarquização ou descrição de momentos na mediação do saber científico. Nesse sentido, recordamos que Brousseau (1986, p. 440-441) explica que "a aprendizagem no contexto da resolução de problemas, evolui a partir da compreensão do papel e função de alguns momentos particulares", condicionados pelo trinômio professor-saber-aluno. Na fig. 8, indicamos (em cor vermelha) elementos condicionados por momentos que envolvem o ensino do TFI, acrescidos das variáveis didáticas que consideramos relevantes em nosso caso. 


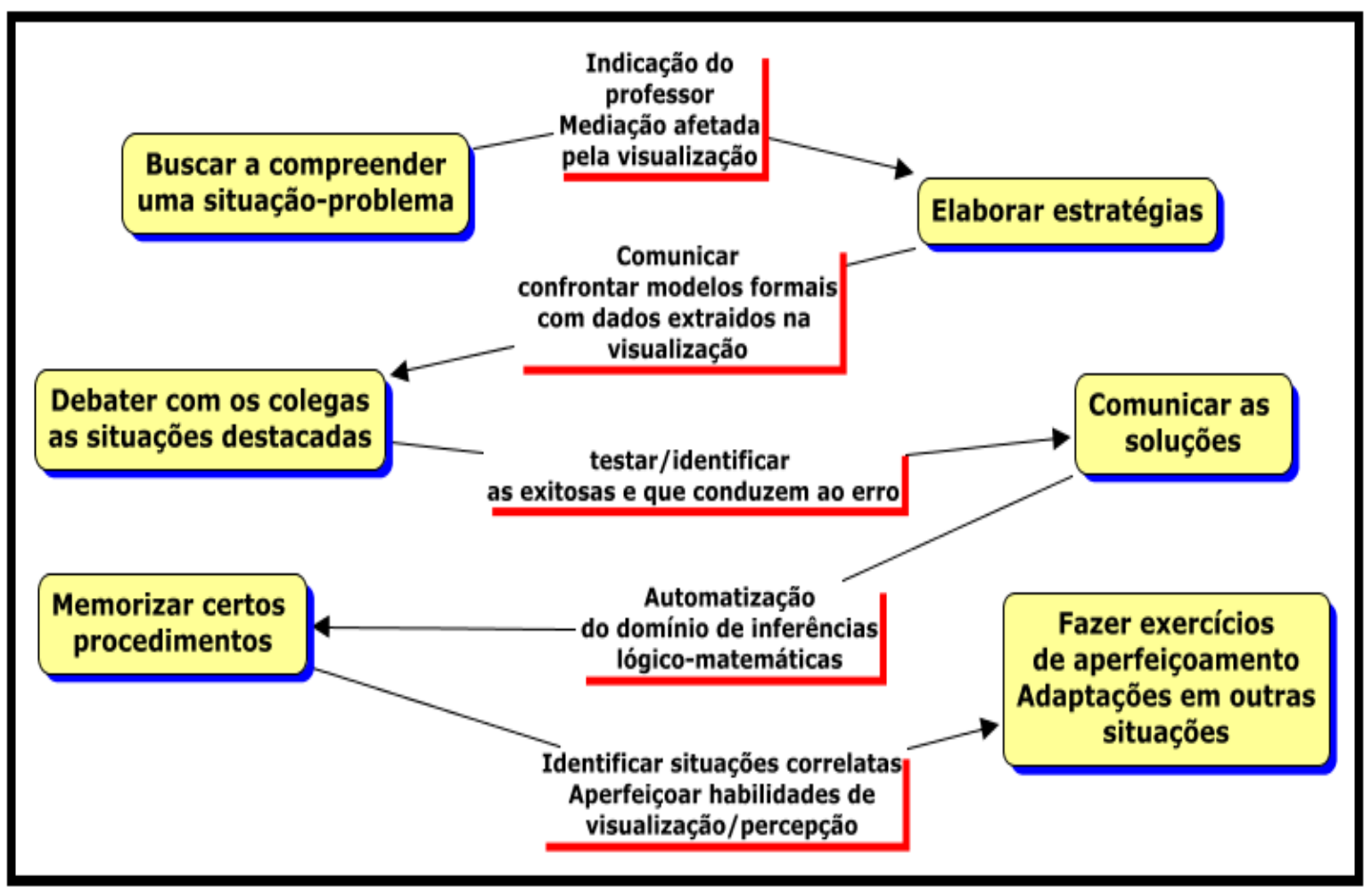

Figura 8 - Adaptação do esquema proposto por Brousseau (1986, p. 440-441)

Na figura 8 acima, na passagem de transição de cada momento didático, antevemos a manifestação de uma decisão tomada (ou várias decisões) pelo sujeito ou pelos sujeitos. Em cada passagem, prevemos "a manifestação de um conhecimento" (BROUSSEAU, 1986, p. 27). Para que o aluno vivencie possibilidades de mobilizar e/ou manifestar seu conhecimento privado, "modelisamos situações" (BROUSSEAU, 1986, p. 400) que possuem o potencial de várias descobertas, em função de suas escolhas e decisões.

O surgimento dessas descobertas e a ocorrência de elementos inesperados e tácitos determinam "o grau de incerteza" (BROUSSEAU, 1986, p. 270). Concordamos, pois, com Brousseau (1986, p, 270) ao destacar que "a aprendizagem de um conhecimento ocorre na medida em que diminui o grau de incerteza" relativa às situações didáticas apresentadas pelo professor em sala de aula.

\subsection{Situações didáticas}

Nessa seção, apresentamos situações-problema relacionadas com o TFI. Vale destacar que "para garantir, minimamente, o alcance desses objetivos, o pesquisador ou o construtor de situações-problema necessita escolher as variáveis didáticas que podem provocar as mudanças desejadas, no que diz respeito ao processo de ensino e de aprendizagem do objeto matemático em jogo" (ALMOULOUD, 2007, p. 174). Desse modo, dentre as variáveis microdidáticas (locais)

DOI: Em andamento. 
que colocamos ênfase, indicaremos: os conteúdos envolvidos nas atividades propostas, os saberes requeridos para o uso da tecnologia. Vejamos, pois, nossa primeira situação.

Situação (I): Considerando a equação, descrita de modo implícito, da maneira $z^{3}+z^{2} y-7 x^{2} y^{2} z+z=0$. Decidir (com base na figura 9) se existe uma função $z=z(x, y)$, definida localmente, na vizinhança do seguinte ponto $(1,1,2)$.

Na figura 9, com o auxilio do CAS Maple, exibimos as superfícies de nível $F(x, y, z)=z^{3}+z^{2} y-7 x^{2} y^{2} z+z=k$, com $k \in\{0,2,4,6\}$, no $I R^{3}$. Proporcionamos o entendimento do comportamento geométrico de uma família de superfícies de nível, que correspondem ao gráfico de uma função descrita por $F(x, y, z)=w$ no espaço $I R^{4}$.

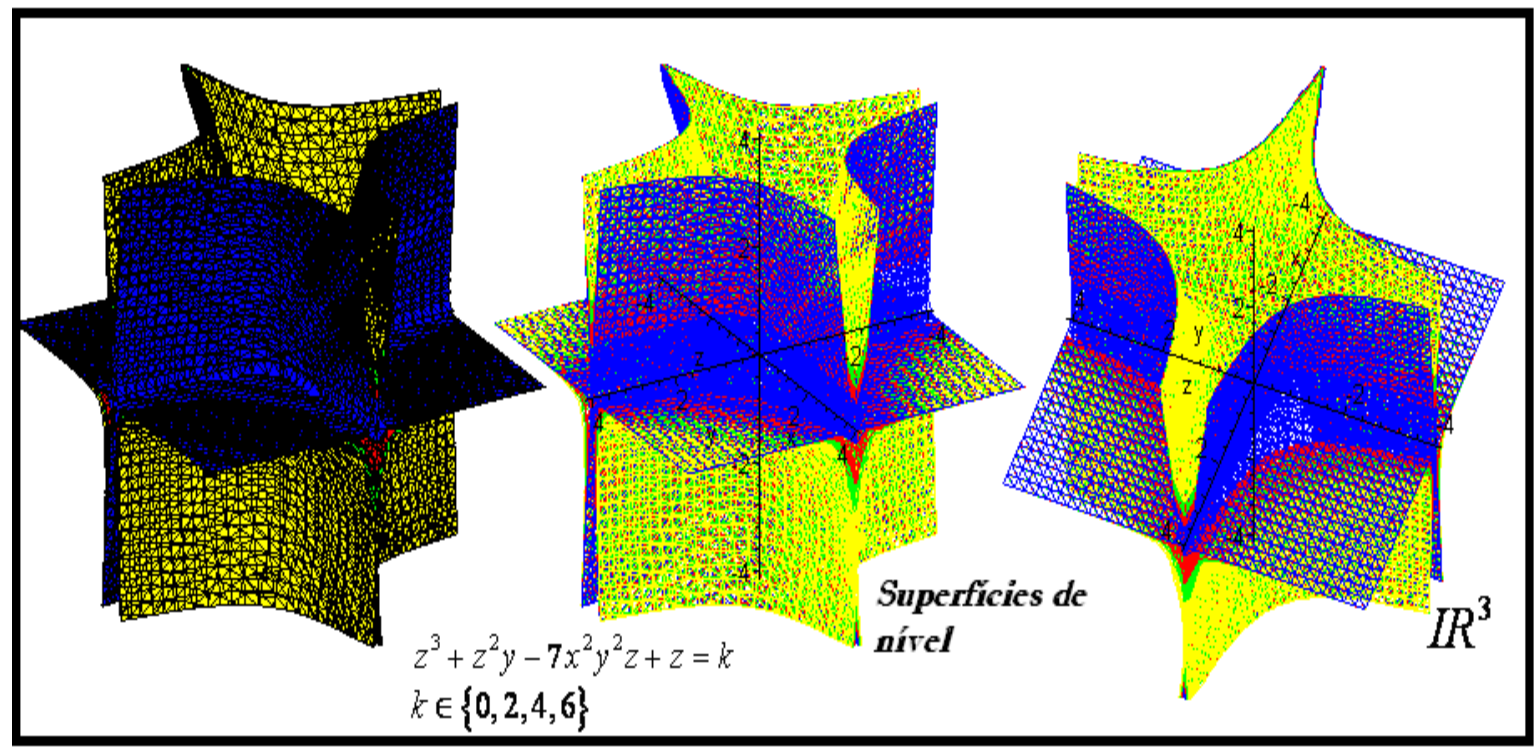

Figura 9-Descrição do comportamento gráfico-geométrico da superfície de nível no espaço (elaboração do autor)

No que concerne a equação $z^{3}+z^{2} y-7 x^{2} y^{2} z+z=0$, por meio da definição da seguinte função $F(x, y, z):=z^{3}+z^{2} y-7 x^{2} y^{2} z+z$. Portanto, escreveremos $\partial z / \partial x(x, y, z)=-(\partial F / \partial x) /(\partial F / \partial z)(x, y, z)=-\left(-14 x y^{2} z\right) /\left(3 z^{2}+2 z y-7 x^{2} y^{2}+1\right) \mathrm{e}$ $\partial z / \partial y(x, y, z)=-(\partial F / \partial y) /(\partial F / \partial z)(x, y, z)=-\left(z^{2}-14 x^{2} y z\right) /\left(3 z^{2}+2 z y-7 x^{2} y^{2}+1\right)$. Assim, escreveremos, $\partial z / \partial x(1,1,2)=28 / 10$ e $\partial z / \partial y(1,1,2)=24 / 10$. Descreveremos ágoras as seguintes retas determinadas por $(z-2)=14 / 5(x-1)$ e $(z-2)=12 / 5(y-1)$. A partir da determinação das retas, indicaremos a descrição do plano que tangencia o gráfico da função "implícita", cuja existência é garantida pelo TFI, do seguinte modo: $\nabla F(x, y, z)=\left(14 x y^{2} z, z^{2}-14 x^{2} y z, 3 z^{2}+2 z y-7 x^{2} y^{2}+1\right) \therefore \nabla F(1,1,2)=(28,-24,10)$.

Por fim, impomos a condição $(14,-12,5) \cdot(x-1, y-1, z-2)=0$. Se o recurso computacional, se torna inexequivel a tarefa didática que envolve a transmissão do significado do 
objeto que exibimos na figura 7 (superfícies de nível). Propriedades do vetor gradiente (HAIRER \& WANNER, 2008, p. 306), como indicamos em $\nabla f\left(x_{0}, y_{0}, z_{0}\right) \cdot\left(x-x_{0}, y-y_{0}, z-z_{0}\right)=0$, pouco significam aos alunos, de modo restrito ao quadro algébrico. Diferentemente, nas próximas situações, acrescentaremos um significado geométrico para todos os elementos obtidos, por intermédio do uso do TFI. Com amparo na visualização, estimulamos a produção de conjecturas.

Situação (II): Vamos considerar a equação $x^{3}+3 y^{2}+8 x z^{2}-3 z^{3} y=9$. Vamos empregar outra técnica. Ela consiste em derivarmos, de modo implícito a equação $x^{3}+3 y^{2}+8 x \cdot z(x, y)^{2}-3 \cdot z(x, y)^{3} \cdot y=9$. Exibimos abaixo, na figura 10 , uma família de superfícies de nível (no espaço $I R^{3}$ ) correspondentes ao problema abordado.

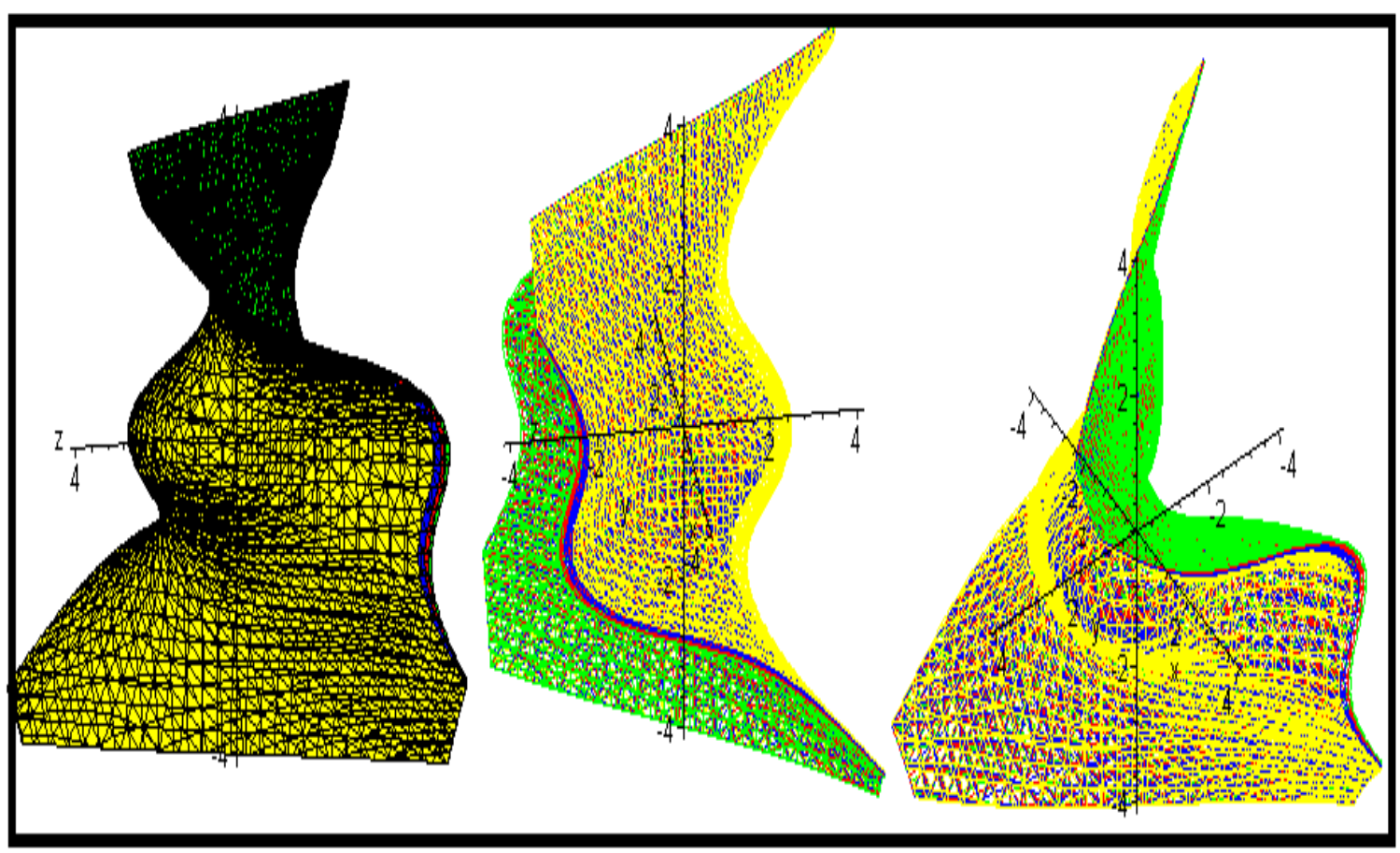

Figura 10 - Descrição do comportamento gráfico-geométrico da superfície de nível no espaço (elaboração do autor)

Derivando em relação a ' $x$ ' escrevemos:

$$
\begin{gathered}
\partial / \partial x\left[x^{3}+3 y^{2}+8 x \cdot z(x, y)^{2}-3 \cdot z(x, y)^{3} \cdot y\right]=0 \therefore \\
3 x^{2}+6 y \partial y / \partial x+8 \cdot z(x, y)^{2}+16 x \cdot z(x, y) \partial z / \partial x-9 y z(x, y)^{2} \partial z / \partial x-3 \cdot z(x, y)^{3} \cdot \partial y / \partial x=0 .
\end{gathered}
$$

Fazendo as seguintes simplificações nas equações algébricas, escrevendo: $3 x^{2}+8 \cdot z(x, y)^{2}+16 x \cdot z(x, y) \partial z / \partial x-9 y z(x, y)^{2} \partial z / \partial x=0 . \quad$ Escrevemos, pois: $\left[16 x \cdot z(x, y)-9 y z(x, y)^{2}\right] \cdot \partial z / \partial x=-\left[3 x^{2}+8 \cdot z(x, y)^{2}\right] \therefore \partial z / \partial x=-\left[3 x^{2}+8 \cdot z^{2}\right] /\left[16 x \cdot z-9 y z^{2}\right]$. Vale observar que procedermos a uma simplificação da notação anterior, podem implicar alguns 
problemas de entendimento ao incipiente (ALVES, 2011). De modo semelhante, derivando a equação, em relação à ' $y$ ', encontraremos que $\partial z / \partial y=-\left[3 z^{3}-6 y\right] /\left[16 x \cdot z-9 y z^{2}\right]$.

A abordagem de Bortolossi (2009, p. 328) permite a descrição que buscamos, embora, o autor não apresente nenhum gráfico que ampare o raciocínio do leitor. Seguindo suas considerações, vamos tomar o ponto $(1,0,1)$ e as declividades no ponto $\partial z / \partial x(1,0,1)=-11 / 16$ e $\partial z / \partial y(1,0,1)=3 / 16$. As retas possuindo essas declividades são descritas por $(z-1)=-11 / 16(x-1)$ e $(z-1)=3 / 16(y-0)$. O vetor gradiente é descrito por $\nabla F(1,0,1)=(11,-3,16)$ e divisamos ser perpendicular o plano determinados por tais retas.

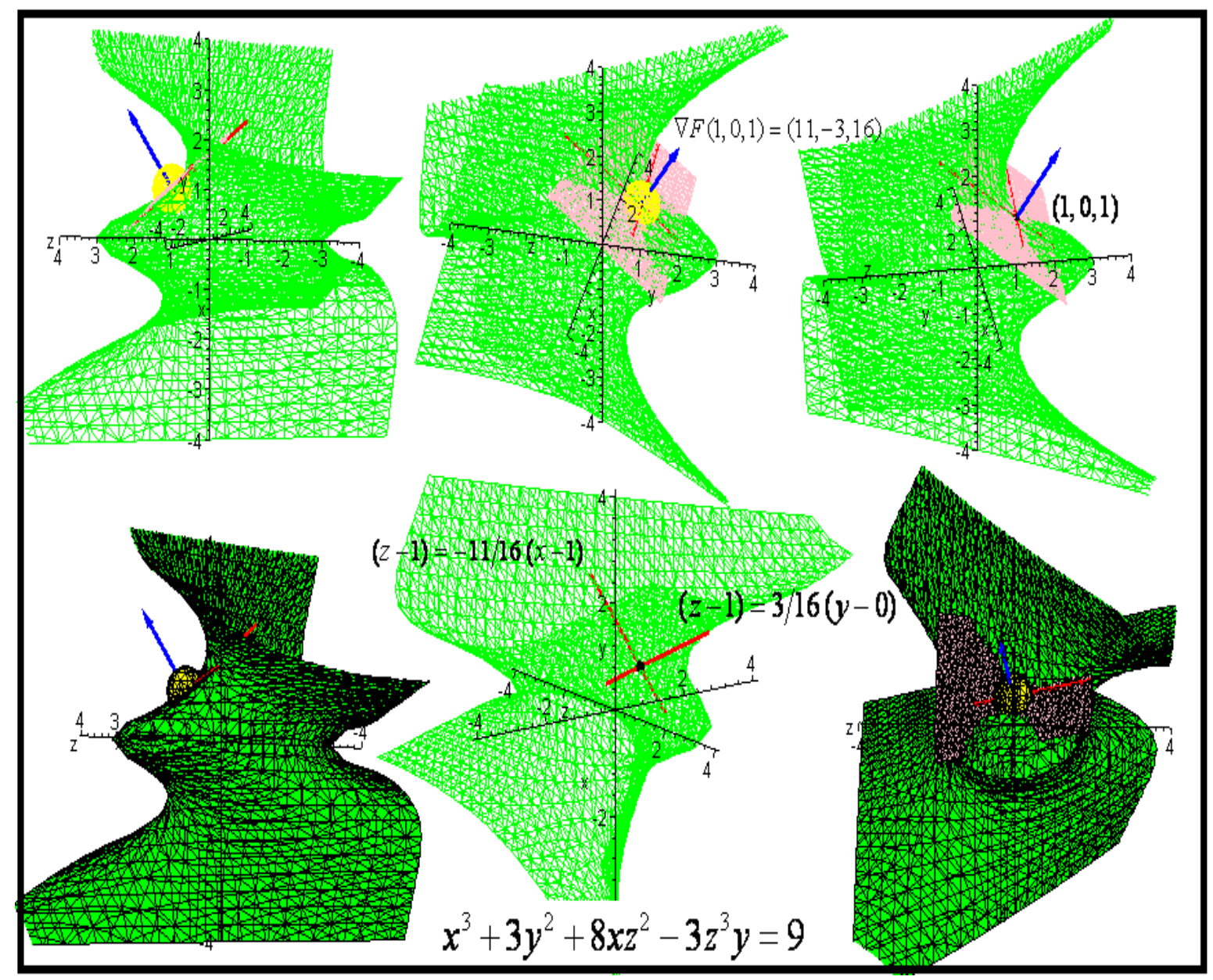

Figura 11 - Descrição do comportamento gráfico-geométrico da superfície de nível no espaço, do plano tangente ao gráfico da função (elaboração do autor)

As condições qualitativas (comportamento do vetor gradiente, existência do plano tangente ao gráfico de uma função "implícita", vizinhança aonde vale o TFI) são apoiadas num movimento perceptual (ALVES, 2012; 2013). Diferentemente de Bortolossi (2009, p. 328) que 
assenta sua exploração apenas no modelo formal e no movimento intuitivo, com origem nesse modelo e nos dados fornecidos ao leitor (ver fig. 11). Passaremos, pois, a nossa ultima situação.

Situação (III): Decidir se a equação $x z^{2}+y^{2} z=e^{x y z}$ define, de modo implícito, $z=z(x, y)$, numa vizinhança do ponto $(1,0,1)$. Com base na figura 12 , descrever analiticamente as retas, que passam no ponto dado, determinando a existência de um plano indicado abaixo.

Com efeito, divisamos uma vizinhança descrita por $(x-1)^{2}+y^{2}+(z-1)^{2}=1 / 4$ (em cor amarela). Indicamos a localização do ponto $(1,0,1)$ (em cor preta) na superfície. As retas (em cor vermelha) são obtidas por meio dos números $\partial z / \partial x(1,0,1)=-1 / 2$ e $\partial z / \partial y(1,0,1)=1 / 2$.

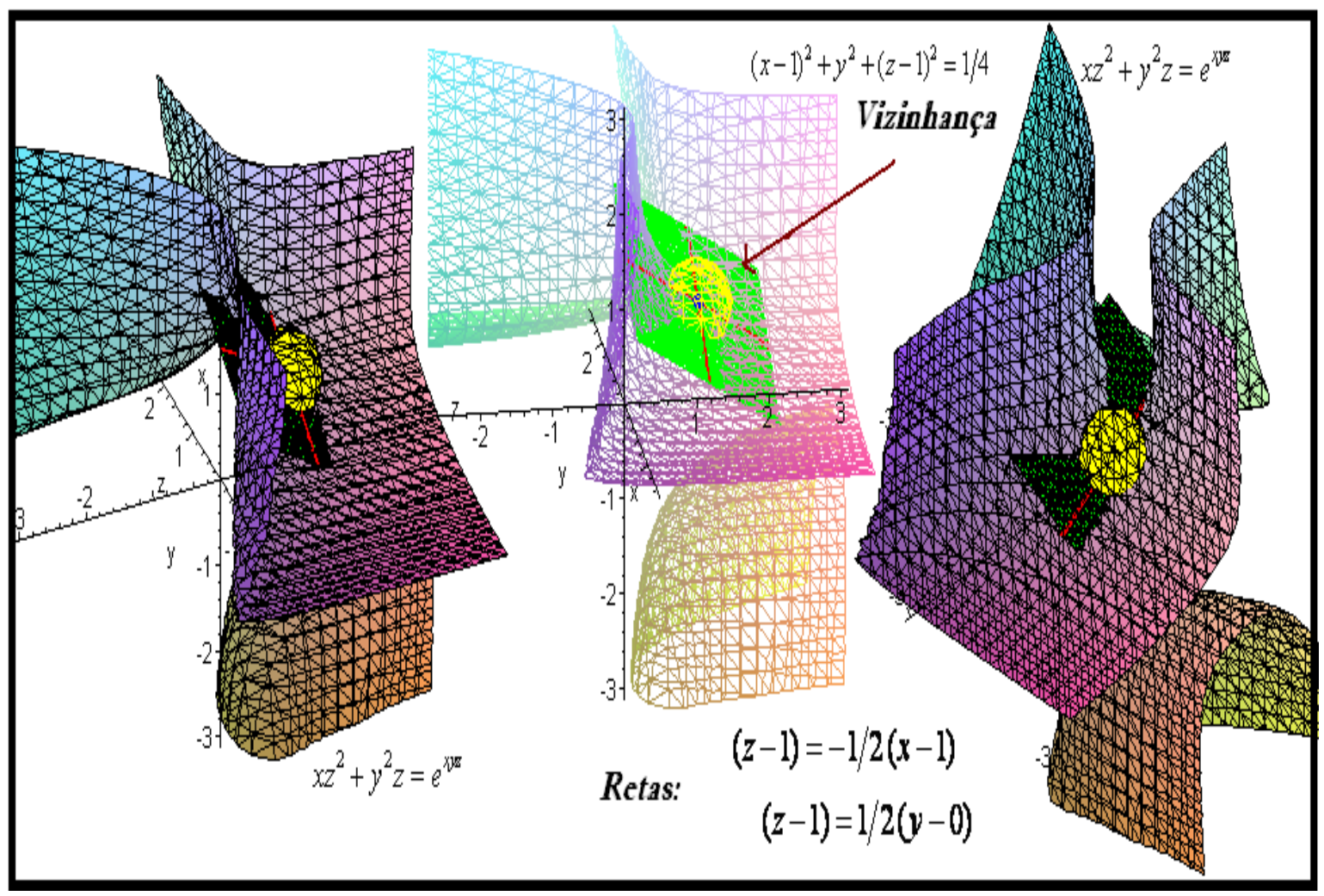

Figura 12 - Descrição dos objetos indicados no enunciado da situaçãoproblema sem a indicação do vetor gradiente, avaliado no ponto $(1,0,1)$ (elaboração do autor)

Brousseau (1986, p. 435) adverte que "na universidade, é freqüente encontramos os estudantes esperando a solução de um exercício de combinatória para adquirirem certeza da resposta correta". No cenário que indicamos na figura 12 , toda a identificação preliminar, com o intuito de compreensão dos dados do problema, depende da visualização e da percepção de propriedades topológicas locais e globais (ALVES, 2012; 2014b). 
Do ponto de vista a sintaxe do CAS Maple, destacamos que os conhecimentos mobilizados não exigem, por parte do professor, grande domínio de programação. Nesse sentido, indicamos:

$>$ with(plots);

$>$ implicitplot3d $\left(\left(x^{*} z^{\wedge} 2+y^{\wedge} 2 * z=\exp \left(x^{*} y^{*} z\right)\right), x=-3 . .3, y=-3 . .3, z=-3.3\right.$, grid=[25,25,25]);

$>$ pointplot3d([1,0,1],symbol=circle,color=blue);display(\%,\%\%);

$>$ implicitplot3d $\left((x-1)^{\wedge} 2+y^{\wedge} 2+(z-1)^{\wedge} 2=1 / 4, x=-3 . .3, y=-3 . .3, z=-\right.$

$3 . .3$,grid=[25,25,25],color=yellow); display $(\%, \% \%)$;

$>$ implicitplot3d $\left(-1 / 2^{*}(x-1)+1 / 2 * y=z-1, x=-0 . .2, y=-\right.$

$1 . .1, z=0 . .2$,grid=[25,25,25],color=green); display $(\%, \% \%)$;

$>$ spacecurve([t,0,1-t/2+1/2],t=0..2,color=red,thickness=4); display $(\%, \% \%)$;

$>$ spacecurve $([1, \mathrm{t}, \mathrm{t} / 2+1], \mathrm{t}=-1 . .1$,color=red,thickness=4);display(\%,\%\%);

Nos commandos acima, cabe esclarecer que: with(plots) abre o pacote de comandos para a produção de gráficos 2D e 3D; implicitplot3d gera o gráfico de equações definidas de modo implícito em duas e três variáveis; spacecurve descreve curvas parametrizadas em 2D e 3D. Por fim, o comando display(\%,\%\%) permite a operação de interseção de até três objetos.

Com base na definição da função $f(x, y, z)=x z^{2}+y^{2} z-e^{x y z}=0$ que determina uma superfície de nível, poderemos obter $\partial z / \partial x(x, y, z)=\left[-z^{2}+y z \cdot e^{x y z}\right] /\left[2 x z+y^{2}-x y \cdot e^{x y z}\right]$ e $\partial z / \partial y(x, y, z)=\left[-2 y z+x z \cdot e^{x y z}\right] /\left[2 x z+y^{2}-x y \cdot e^{x y z}\right]$, com a restrição $2 x z+y^{2}-x y \cdot e^{x y z} \neq 0$.

Para a determinação do plano (em cor verde), podemos prever o uso de duas formulações. Na primeira, pelo TFI, determinamos uma região e nela, teremos um "pedaço" do gráfico de uma função $z=z(x, y) \therefore z-z_{0}=\partial z / \partial x\left(x_{0}, y_{0}\right)\left(x-x_{0}\right)+\partial z / \partial y\left(x_{0}, y_{0}\right)\left(y-y_{0}\right)$ é a equação do plano tangente a gráfico, no ponto $(1,0,1)$, dada existência, todavia, "implícito"!

Outra maneira é observar que o vetor gradiente $\nabla f(1,0,1)=(1,1,1)$ é perpendicular a todo vetor nesse plano tangente ao gráfico da função "implícita" no ponto $(1,0,1)$, isto é, escrevemos $\nabla f(1,0,1) \cdot(x-1, y-0, z-1)=0$. Sua propriedade foi constatada na situação (II) e, com respeito ao software, para acrescentar ainda o vetor gradiente da situação (III), indicamos:

$>\operatorname{arrow}([1,0,1],<1,1,1>$,length=2,color=blue,scaling=constrained,view=[-4..4,-4..4,--

4..4]);display(\%,\%\%);;display(\%,\%\%);

Como ultimo exemplo (fig. 13), indicamos situações-problema em que não pudemos contar com a interpretação gráfico-geométrica. Basta notar que na figura abaixo, temos superfícies de nível $F(x, y, z, w)=0$ e $G(x, y, z, w)=0$, cujos gráficos estão no espaço $I R^{5}$. Kaplan (1993) estimula o leitor desconsiderar qualquer preocupação com as condições suficientes para o uso do TFI e com a existência de soluções. Em situações como essas, a ação do estudante é guiada/determinada, de modo exclusivo, pelo modelo e descrição formal, que permite a aplicação 
de inferências lógicas e extração de conclusões. Os elementos que despertam a percepção e a visualização se restringem ao reconhecimento organizacional dos registros, símbolos ou notações que detém, possivelmente, a capacidade de proporcionar ao solucionador desse problema, o link conceitual conveniente, todavia, constitui "terreno pouco adequado ao surgimento de um insight" (ALVES, 2012), visto que, determina um único procedimento/argumento algébrico a ser escolhido.

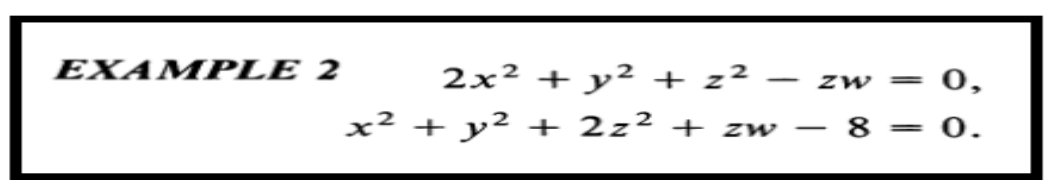

Figura 13 - Exemplo standard abordado em Kaplan (1993, p. 109)

\section{Considerações finais}

No locus acadêmico os rituais de ensino tendem a privilegiar o caráter algoritmizado dos procedimentos. A apresentação acadêmica ou enciclopédica (BROUSSEAU, 1986, p. 475) é eficiente para os experts. Todavia, ocorre o predomínio de uma concepção limitada e questionável que atribui uma razão suficiente, segunda a qual, "para o entendimento do aprendiz, exige-se o simples trato ou emprego e uso de teoremas" (Lozada-Crus, 2012, p. 74). Por outro lado, para a descrição de atividades que detêm a possibilidade de suavizar ou, pelo menos evitar tal caráter formalista, é necessário um bom planejamento para a preparação de uma aula. Neste sentido, nos apoiamos neste artigo, somente na descrição das etapas iniciais previstas pela ED (análise preliminar, construção de atividades e análise a priori) para os momentos de desenho e da produção de sequências de ensino (GONZALEZ-MARTíN, 2005, p. 118), envolvendo o TFI.

Nas análises a priori e para a construção de situações, vimos que a exploração da tecnologia, em nosso caso do CAS Maple, possibilitou a descrição de situações-problema, condicionados pela visualização, com origem na percepção (ALVES, 2011; 2012; 2013; 2014a; 2014b) e o entendimento do papel/função e significado de elementos proeminentes nos gráficos exibidos. Além disso, nas figuras construídas e relacionadas com cada cenário de aprendizagem, promovemos o entendimento topológico local (e particular), de validade do TFI e suas propriedades previstas.

O destaque da visualização, entretanto, viabilizada em nosso caso pela tecnologia constitui, de maneira geral, o esforço isolado, que influencia ainda de modo tímido o ensino na academia, "acentuadamente formal" (ARTIGUE, 2003, p. 119). Com efeito, o que assinalamos na análise de livros, sob um viés particular, é alertado, de modo amplo, por Artigue (1995, p. 40) quando adverte que "o ensino tradicional se centra no funcionamento do quadro algébrico". 
A metodologia que adotamos, tendo em vista a descrição de ações didáticas, chamada de $E D$, pode ser compreendida como "uma teoria de controle das relações entre significados e situações" (ARTIGUE, 1995, p. 44-45). Tendo em vista esse posicionamento, reduzimos a hegemonia de uma apresentação funcional (BROUSSEAU, 1986, p. 476) que se resume a atividade de investigação matemática ao cálculo/ação sobre um algorítmico específico. Em nosso cenário de aprendizagem, o professor poderá estimular a produção de sentenças proposicionais, a partir da interação e manipulação dos gráficos (fig. 2, 7, 8,9 e 10) produzidos por ambos os softwares.

Quando o professor manifesta o interesse por outras vias de abordagem (distinta da condução dos autores de livros), novas formas de significação e entendimento das noções matemáticas podem ocorrer. Nesse sentido, Douady $(2008$, p. 2$)$ indica a importância de:

"Transferir um problema de um quadro de representação para outro quadro é um meio para que os alunos tomem consciência das propriedades das noções matemáticas em cada quadro e meio pelo qual intervêm no raciocínio. É um meio para os professores trabalhar com os alunos a questão de coerência dos resultados obtidos por meio de diferentes pontos de vista."

A partir da estruturação/aplicação das situações-didáticas aqui apresentadas, "podemos nos interessar por interações específicas, ao longo do decurso de modificações de um sujeito, em seu repertório, com vistas o aprendizado de um novo conhecimento particular" (BROUSSEAU, 2004 , p. 7). Todas as situações, todavia, dependem da tecnologia e visam proporcionar a apreensão conceitual de um novo conhecimento, que supera os condicionantes lógicos.

No que concerne ao uso do software, as situações anteriores não exigem grande conhecimento em programação e sintaxe do CAS Maple. A ação dos comandos envolve, basicamente, a plotagem de gráficos no espaço $I R^{3}$ (plot3d) e a interseção de objetos (display(\%,\%\%,\%\%\%), no caso a interseção de três objetos. Maiores detalhes podem ser encontrados em Alves \& Borges Neto (2012). Na década de 90, Artigue (1997, p. 147) acentuava a importância de se evidenciar as características emergentes num milieu que integra a utilização do software Derive. De modo similar, sublinhamos as distinções, do uso didático de situaçõesdidáticas, com o tema TFI, que envolvem o uso dos softwares Geogebra e do CAS Maple (ALVES, 2014b). Para efetivarmos tal integração, prevemos um empenho/dedição extrassala. Na figura 10, trazemos, com o recurso ao software (o comando intersecplot3d) a identificação da região (curva) de interseção entre dois objetos no espaço $I R^{3}$. O caráter de diferenciabilidade (da curva de intersecção) poderá ser constatado, do ponto de vista intuitivo e visual. (ver fig. 14).

164 DOI: Em andamento. 


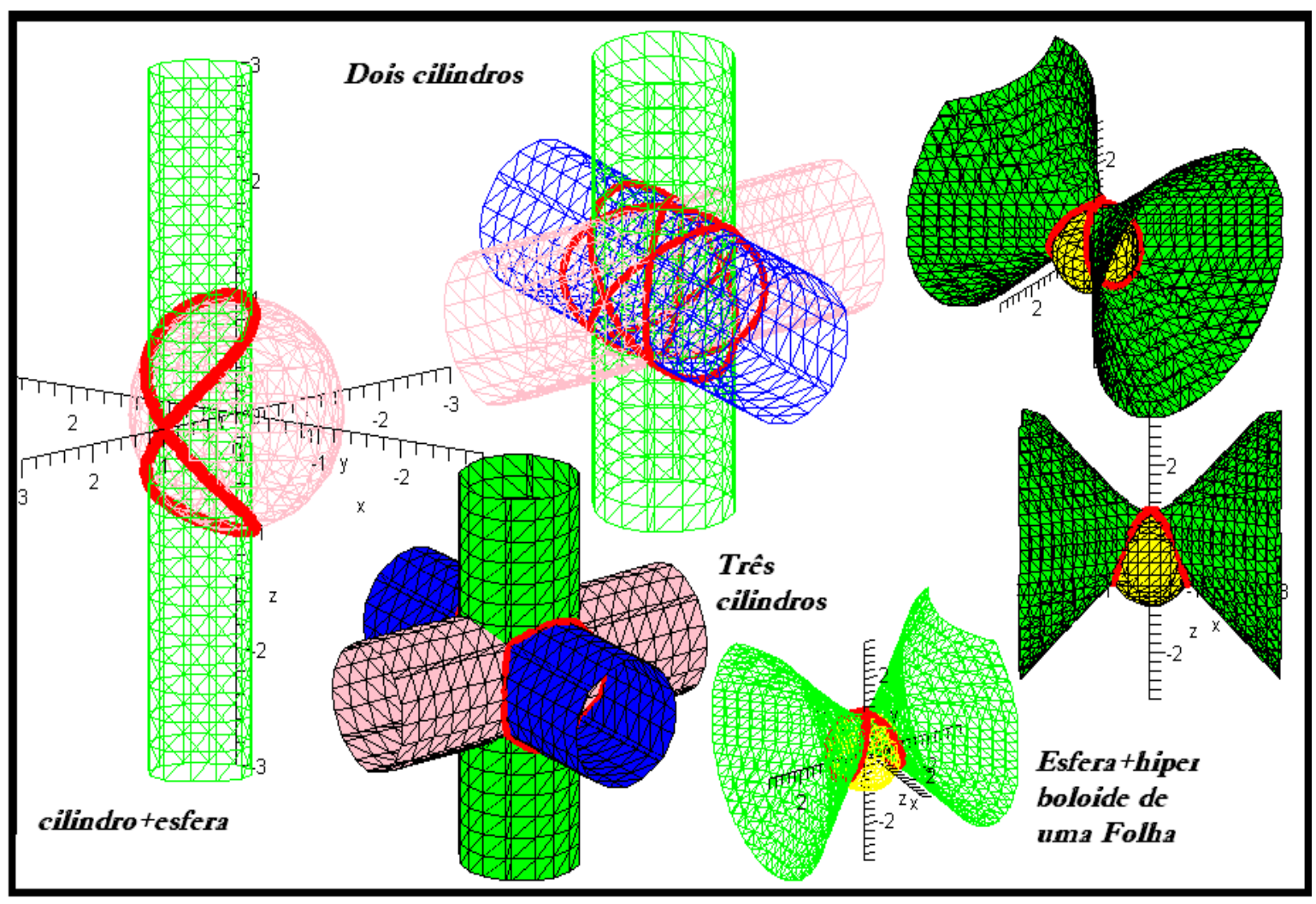

Figura 14 - Exemplos de produção de curvas resultante da interseção de objetos

Por fim, grande parte dos livros de Cálculo a Várias Variáveis consultados possui algumas décadas de lançamento, reedições e reimpressões. $O$ docente deve ficar vigilante, quanto ao "envelhecimento das situações" (BROUSSEAU, 1986, p. 293) propostas nesses compêndios. A "reprodução/replicação" (GONZALEZ-MARTíN, 2005, p. 121) automática dessas situações, para públicos diferentes, pode proporcionar entraves às adaptações e transposições didáticas necessárias, pois, não se pode prever os mesmos resultados, para públicos (de alunos) distintos em ocasiões únicas, embora a abordagem possa parecer ser a mesma. Nesse sentido, a tecnologia impulsiona modificações e reformulações periódicas nas sequências de ensino com esse tema.

E "a transposição didática depende fundamentalmente das concepções que os professores ou os sujeitos possuem a respeito do pensamento matemático" (BROUSSEAU, 1986, p. 277). Na proposta de nossa abordagem, não buscamos indicar um caminho "melhor" para a transposição ou a mediação científica, demarcando com isto que, a outra forma de mediação/transposição tradicional (sem a exploração da tecnologia), seja entendida como "pior". O que buscamos é indicar formas diferenciadas e distintas, das atuais propostas nos livros de CVV e que, em maior ou menor grau, influenciam as concepções e o pensamento matemático dos alunos, professores e matemáticos profissionais, que atuam em nossas academias. 


\section{Referências}

ALVES, Francisco. R. V. Aplicações da Sequência Fedathi na promoção das categorias do raciocínio intuitivo no Cálculo a Várias Variáveis. Fortaleza: UFC, 2011, 399 p. Tese (Doutorado) Programa de Pós-graduação em Educação Brasileira, Universidade Federal do Ceará, Fortaleza, $399 f$.

ALVES, Francisco Régis Vieira. INSIGHT: DESCRIÇÃO E POSSIBILIDADES DE SEU USO NO ENSINO DO CÁLCULO. In: Vidya (Santa Maria. Online), v. 32, 2012. p. 149-161. Disponível em: http://sites.unifra.br/Portals/35/2012/10.pdf. Acessado em: 26 de maio de 2013.

ALVES, Francisco. R. V. \& BORGES NETO, Hermínio. Aplicação e exploração da tecnologia no ensino do Cálculo: os softwares Geogebra e o CAS Maple. In: Anais da VI BIENAL da Sociedade Brasileira de Matemática, Campinas, 2012, p. 1-12. Disponível em: http://bienaldematematica.org.br/node/4725. Acesso em: 14 de maio 2013.

ALVES, Francisco. R. V. Viewing the roots of polynomial functions in complex variable: the use of Geogebra and the CAS Maple. Acta Didactica Naposcencia. Romania, v, 6, 2013, no 3, 58-45. Disponível em: http://adn.teaching.ro/. Acesso em: 14 de dezembro 2013.

ALVES, Francisco. R. V. Visual critérion for understanding the notio of convergence of integrals in one parameter. Acta Didactica Naposcencia, Romania, v, 7, 2014a, no 1, 19-30. Disponível em: http://adn.teaching.ro/. Acesso em: 10 de janeiro 2014.

ALVES, Francisco. R. V. Computational Technique for Teaching Mathematics - $C T^{2} M:$ sobre construção de curvas parametrizadas. Boletim Online de Educação Matemática - BoEM. UDESC. 2014b, v. 4, no 2, 56-71. Disponível em: http://revistas.udesc.br/index.php/boem/index. Acesso em: 10 de janeiro 2014.

APOSTOL, Tom. Calculus. v. 2, New York: Handcover, 1967.

ARTIGUE, Michelle. Didactical design. In: Mathematics Education. En Winslon, Carl. (ed.) Nordic Research in Mathematics Education. NORMA08, 2008, p. 7-17. https://www.sensepublishers.com/files/9789087907839PR.pdf. Consultado 20/02/2012.

ARTIGUE, Michelle. Qué se Puede Aprender de la Investigación Educativa en el Nível Universitário?, Boletín de La Asociatíon Venezolana, v. 10, no 2, 2003, p. 117- 134.

ARTIGUE, Michelle. Analysis. In: TALL. D. Advanced Mathematical Thinking. New York: Klumer Academic Publishers, 2002, p.

ARTIGUE, Michelle. Le logiciel "DERIVE" comme révélateur de phénomènes didactiques lies a I'utilisation d'environnement informatiques pour l'apprentissage. In: Educational Studies in Mathematics, 1997, p. 133-169. 
ARTIGUE, Michelle. Ingénierie didactique, In: BRUN, J. Didactiques des Mathématiques, Paris: Delachaux et Niestlé, 1996, p. 243-264.

ARTIGUE, Michelle. Ingeniería Didática. In: ARTIGUE, Michelle; DOUADY, Régine; MORENO, Luiz \& GOMEZ, Pedro. Ingeniería Didática en Educación Matemática. 1995, p. 61-97.

ALMOULOUD, Ag Saddo. Fundamentos da Didática da Matemática. São Paulo: Editora UFPR. (2007).

AYRES, F. \& MENDELSON, E. Schaum's outline of Theory and Problems of Differential and Integral Calculus, Third Edition, New York: McGraw-Hill, 1990.

BORTOLOSSI, Humberto. Cálculo Diferencial a Várias Variáveis: uma introdução a Teoria da Otimização. Rio de Janeiro: PUC/RJ. 2009.

BOYER, Carl. The History of the Calculus and its Conceptual Development, New York: Dover Publications, 1949.

BOYER, Carl. The concepts of the Calculus: a critical and historical discussion of the derivative and the integral. New York: Columbia University Press, 1959.

BROUSSEAU, Guy. Théorisation de phénomènes d'enseignement des mathématiques. (thése de doctorat). Bordeaux : Université de Bordeaux I. 1986. $905 f$.

BROUSSEAU, Guy. L'émergence d'une science de la didactique des mathématiques. In: Repère IREM, 55, 2004. p. 19-34

BUCK, R. C. Advanced Calculus, Second Edition, New York: McGraw-Hill Book Company, 1965.

CAMACHO, Alberto. \& AGUIRRE, Mônica. Situación didática del concepto de límite infinito: análisis preliminar. Revista Latinoamericana de Investigacion en Matematica Educativa. Novembro, v. 4, no 3, 2001, p. 237-265.

DONTCHEV, Asen, L. \& ROCKAFELLER, Tyrrell. R. Implicit functions and solutions Mappings: a view from variational analysis. New York: Springer, 2009.

DOUADY, Régine. Géométrie, graphiques, fonctions au collège. In: Revista Eletrónica de investigación en educación e ciencias. № 1, 2008, p. 1-7.

GONZALEZ-MARTÍN, Alexandro. S. La generalización de la integral definida desde las perspectivas numérica, gráfica y simbólica utilizando entornos informáticos. Problemas de enseñanza y de aprendizaje (teses doctorales). Laguna: Universidad La Laguna, 2005. $498 f$.

GHOSHI, J. D. How to learn Calculus of one Variable. New Delhi: New Age Limited Publishers, 2004.

GUIDORIZZI, H. Um curso de Cálculo, vol.2, Rio de Janeiro: Livros Técnicos e Científicos, 2010.

HAIRER, E. \& WARNER, G. Analysis by Its History, New York: Springer, 2008.

R. B. E. C. T., vol 7, núm. 3, set-dez.2014 ISSN - 1982-873X

DOI: Em andamento. 
HENRIQUES, Afonso. L'enseignement et l'apprentissage des integrales multiples: analyse didactique integrant l'usage du logiciel Maple (Thèse de Doctorat), Grenoble: Université Joseph Fourier, IMAG, 2006, 320p.

JUNKINS, John. L.; TURNER, James. D. \& MANORAJAN, Majji. Generalisation and Application of Lagrange Implicit Theorem Function. In: The Journal of Astronautical Sciences. v. 57. no 1 e 1, January. 2009, p. 313-345.

KAPLAN, Wilfred. Advanced Calculus. Fourth edition. California: Addison-Weley Publishers Company. 1993, $763 f$.

KRANTZ, Steven. G. \& PARKS, Harold, R. The implicit function theorem: history, theory and application. Boston: Birkhaüser, 2001.

LIMA, E. L. Curso de Análise, v. 2, Rio de Janeiro: IMPA, 2009.

LOZADA-CRUZ, German. The simple application of the implicit function theorem. Boletin de la Asociatión Matemática Venezolana. v. XIX, no1. 2012. Acessado em 2 fev. 2013. Disponivel: http://www.emis.de/journals/BAMV/conten/vol19/BAMV XIX-1 p071-

076.pdfhttp://www.emis.de/journals/BAMV/conten/vol19/BAMV XIX-1 p071-076.pdf.

LEITHOLD, Luois. O Cálculo. v. 2, 3a edição, São Paulo: Editora Harbra, 1999.

PINTO, Diomara. \& MORGADO, Maria. C. F. Cálculo Diferencial e Integral de Funções de Várias Variáveis. 3a edição. Rio de Janeiro: Editora UFRJ, 2000.

ROBINET, Jacqueline. De l'ingenierie didactiques. Cahier Didactiques des Mathematiques. 1983, no 1, 1-10.

SCARPELLO. Giovani. \& RITELLI. Danielle. A historical outline of the Theorem of Implicit Function. In: Divulgaciones matematicas. v. 10, no 2, 2002, p. 171-180. Disponível em: http://www.emis.de/journals/DM/vol10-2.htm. Acessado em: 9 de julho de 2012.

STEWART, J. Cálculo, v. 2, 4ạ edição, São Paulo: Pioneira Thompson Learning, 2004.

SWOKOWSKI, Earl. W. Calculus with Analytic Geometry. Boston: Prindle, Weber e Schmidt, 1983.

WIDER, D. Advanced Calculus. New York: Prentice Hall, 1947.

Francisco Regis Vieira Alves - Doutor em Educação com ênfase no ensino de Matemática. Prof. do departamento de Matemática. Docente do Mestrado Profissional em Ensino de Ciências e Matemática - ENCIMA/UFC. Email: fregis@ifce.edu.br 